\title{
Pengetahuan sebagai Faktor Dominan Efikasi Diri Kader dalam Melakukan Deteksi Dini Gangguan Jiwa
}

\section{Knowledge as the Dominant Factor in Improving Self-Efficacy of Cadre in Performing Early Detection of Mental Disorder}

\author{
Yanti Rosdiana ${ }^{1}$, Edi Widjajanto ${ }^{2}$, Rinik Eko $K^{3}$ \\ ${ }^{1}$ Program Studi Magister Keperawatan Fakultas Kedokteran Universitas Brawijaya Malang \\ ${ }^{2}$ Laboratorium Patologi Klinik Fakultas Kedokteran Universitas Brawijaya Malang \\ ${ }^{3}$ Departemen Keperawatan Fakultas Kedokteran Universitas Brawijaya Malang
}

\begin{abstract}
ABSTRAK
Kader kesehatan jiwa berperan penting di masyarakat dalam pelaksanaan deteksi dini gangguan jiwa. Pengetahuan, pengalaman, dan dukungan sosial merupakan sebagian dari faktor yang diduga mempengaruhi efikasi diri kader dalam melakukan deteksi dini. Tujuan penelitian ini untuk mengetahui hubungan tiap faktor dengan efikasi diri kader dan mengetahui faktor dominan yang mempengaruhi efikasi diri kader. Penelitian ini menggunakan desain observasi analitik dengan pendekatan cross sectional. Sebanyak 138 sampel yang memenuhi kriteria inklusi diambil secara proporsional dari lima desa di wilayah kerja Puskesmas Bantur Kabupaten Malang. Data dianalisis secara deskriptif dan dilakukan uji regresi logistik untuk mengetahui faktor dominan yang meningkatkan efikasi diri kader. Hasil menunjukkan kader adalah ibu rumah tangga pada usia produktif dengan latar belakangan pendidikan menengah. Secara umum kader telah memiliki pengetahuan, pengalaman, dan dukungan sosial yang baik dalam melakukan deteksi dini ganggungan jiwa. Uji regresi logistik menunjukkan kader yang memiliki pengetahuan tinggi akan meningkatkan 6,853 kali efikasi diri (OR=6,853, $p=0,007$ ) dibandingkan kader yang memiliki pengetahuan rendah. Pengetahuan, pengalaman dan dukungan sosial yang baik akan meningkatkan efikasi diri kader dalam melakukan deteksi dini gangguan jiwa dengan pengetahuan sebagai faktor dominan.
\end{abstract}

Kata Kunci: Deteksi dini gangguan jiwa, efikasi diri kader, pengetahuan

\begin{abstract}
Cadres of mental health play an important role in the community in the application of early detection of mental disorders. Knowledge, experience, and social support are some of the factors that are assumed to influence cadre's self-efficacy in conducting early detection. The purpose of this study was to determine the relationship of each factor with cadre's selfefficacy and to find out the dominant factors that influence cadre's self-efficacy. This study used an analytical observation design with a cross sectional approach. A total of 138 samples that met the inclusion criteria were taken proportionally from five villages in the working area of Bantur Health Center Malang Regency. Data were descriptively analyzed, and logistic regression tests were conducted to determine the dominant factors that increase cadre's self-efficacy. The results show that cadres are housewives of productive age with a background of secondary education. In general, cadres have knowledge, experience, and good social support for early detection of mental disorders. Logistic regression test shows cadres who have high knowledge will increase 6.853 times self-efficacy $(O R=6.853, p=0.007)$ compared to cadres who have low knowledge. Knowledge, experience, and good social support will increase cadre's self-efficacy in early detection of mental disorders with knowledge as the dominant factor.
\end{abstract}

Keywords: Early detection of mental disorders, knowledge, self-efficacy of cadre

Korespondensi: Yanti Rosdiana. Program Studi Magister Keperawatan Fakultas Kedokteran Universitas Brawijaya Malang. Jl. Veteran Malang 65145 Tel.08164251646Email:dr.agungptr@gmail.com

DOI: http://dx.doi.org/10.21776/ub.jkb.2018.030.02.11 


\section{PENDAHULUAN}

Gangguan jiwa merupakan permasalahan kesehatan global. Di seluruh dunia, terdapat sekitar 35 juta orang mengalami depresi, 60 juta orang mengalami bipolar, 21 juta mengalami skizofrenia dan 47,5 juta mengalami dimensia (1). Data Riskesdas tahun 2013 menunjukkan bahwa prevalensi gangguan jiwa berat di Jawa Timur sebesar 2,2 per 1000 penduduk atau menduduki peringkat tertinggi ke-3 di Indonesia (2). Angka tersebut mungkin lebih rendah dari angka sebenarnya karena adanya stigmatisasi (pelabelan) pada pasien gangguan jiwa yang menyebabkan ketakutan pada penderita itu sendiri, keluarga dan masyarakat sehingga tidak melaporkan ke tenaga kesehatan (3).

Pengelolaan permasalahan gangguan jiwa pada pelayanan primer merupakan strategi penting. Community Mental Health Nursing (CMHN) merupakan salah satu program di Puskesmas yang mengikutsertakan tokoh masyarakat dalam upaya pelaksanaan penurunan angka gangguan jiwa. Tokoh masyarakat tersebut kemudian dilatih dan dijadikan kader kesehatan jiwa dengan harapan masyarakat dekat dengan pelayanan kesehatan jiwa. Salah satu peran kader kesehatan jiwa adalah melakukan deteksi dini gangguan jiwa pada keluarga yang bertujuan untuk mengetahui kondisi kesehatan jiwa pada keluarga (4).

Pelaksanaan deteksi dini gangguan jiwa yang dilakukan oleh kader kesehatan jiwa sangat dipengaruhi oleh efikasi diri kader. Efikasi diri merupakan keyakinan seseorang dalam kemampuannya untuk menjalani perilaku yang sesuai dengan tujuannya (5). Faktor-faktor yang mempengaruhi efikasi diri kader di antaranya adalah pengetahuan yang baik akan mendorong seseorang dalam meyakini apa yang dilakukannya (6). Hasil penelitian sebelumnya menunjukkan bahwa faktor lain yang mempengaruhi efikasi diri adalah pengalaman. Pengalaman merupakan kejadian-kejadian yang pernah dialami sebelumnya dengan demikian maka akan meningkatkan efikasi diri pada seseorang dalam melakukan tugasnya (5). Penelitian lain juga menunjukkan bahwa faktor lain yang mempengaruhi efikasi diri adalah dukungan sosial. Dukungan sosial yang berasal dari lingkungan keluarga, teman atau orang lain akan membuat seseorang yakin pada apa yang dilakukannya (7).

Jumlah pasien yang terdeteksi menggalami gangguan jiwa berat di wilayah Puskesmas Bantur pada tahun 2017 adalah sebanyak 134 jiwa, dengan jumlah kader 210 orang kader. Peran kader kesehatan jiwa ini sangat membantu dalam menurunkan angka gangguan jiwa yang ada di masyarakat, karena dengan adanya kader kesehatan jiwa bisa mengambarkan jumlah gangguan jiwa yang belum terdeteksi yang ada di masyarakat (4). Penelitian ini dilakukan untuk mendeskripsikan efikasi diri kader dan faktor yang mempengaruhinya. Hasil penelitian dapat menjadi dasar dalam menguatkan peran kader kesehatan jiwa untuk mendeteksi gangguan jiwa pada masyarakat.

\section{METODE}

Desain penelitian ini menggunakan observasional analitik dengan pendekatan cross sectional. Penelitian ini telah mendapatkan izin dari Komite Etik Penelitian Kesehatan (KEPK) Fakultas Kedokteran Universitas Brawijaya (No. 02/EC/KEPK-S2/01/2018). Penelitian dilakukan di Wilayah Puskesmas Bantur pada bulan Januari-Maret 2018.
Instrumen penelitian yang digunakan dalam penelitian ini adalah kuesioner untuk mengukur pengetahuan (8), pengalaman (9), dukungan sosial (10), dan efikasi diri (11).

\section{Populasidan Sampel}

Populasi dalam penelitian ini adalah semua kader kesehatan jiwa di wilayah Puskesmas Bantur yaitu 210 orang kader kesehatan jiwa. Sampel penelitian ini adalah 138 orang kader yang telah dihitung dengan menggunakan rumus Slovin. Pengambilan sampel dilakukan secara merata dari 5 desa. Responden dipilih dengan kriteria inklusi: 1) sudah bekerja menjadi kader kesehatan jiwa kurang lebih 6 bulan, 2) berusia 25-45 tahun, 3) bersedia terlibat dalam penelitian.

\section{Analisis Data}

Data demografi dan karakteristik responden disetiap variabel, disajikan dalam persentase. Analisis multivariat menggunakan analisis regresi logistik untuk mengetahui faktor yang paling dominan terhadap efikasi diri kader dalam melakukan deteksi dini gangguan jiwa.

\section{HASIL}

Secara demografi kader sebagian besar berada pada usia produktif (25-35 tahun) dengan pendidikan menengah (SMP dan SMU). Kader kesehatan yang terlibat dalam penelitian sebagian besar merupakan ibu rumah tangga.

Tabel 1. Karakteristik umum responden

\begin{tabular}{cllrr}
\hline No. & \multicolumn{2}{c}{ Karakteristik } & n & \multicolumn{1}{c}{$\%$} \\
\hline 1. & Usia Kader & $25-35$ tahun & 72 & 52,2 \\
& & $36-45$ tahun & 66 & 47,8 \\
& & Total & 138 & 100 \\
2. & Pendidikan Kader & SD & 17 & 12,3 \\
& & 72 & 52,2 \\
& & SMP & 46 & 33,3 \\
& SMU & 3 & 2,2 \\
& & PT & 138 & 100 \\
3. & Pekerjaan Kader & 95 & 68,8 \\
& & Total & 25 & 18,1 \\
& & IRT & 16 & 11,6 \\
& Swasta & 2 & 1,4 \\
& & Petani & 138 & 100 \\
\hline
\end{tabular}

Hasil (Tabel 2) menunjukkan bahwa sebagian besar yaitu sebanyak 73 orang $(52,9 \%)$ mempunyai pengalaman yang baik, dukungan sosial tinggi $(68,8 \%)$. Kader juga memiliki pengetahuan $(88,4 \%)$ dan efikasi diri yang tinggi $(62,3 \%)$.

Tabel 2. Gambaran pengalaman, dukungan sosial, pengetahuan, dan efikasi diri kader

\begin{tabular}{cclrc}
\hline No. & \multicolumn{2}{c}{ Karakteristik } & $\mathbf{n}$ & \% \\
\hline 1 & Pengalaman & Kurang & 23 & 16,7 \\
& & Sedang & 42 & 30,4 \\
& & Baik & 73 & 52,9 \\
& & Total & 138 & 100 \\
2 & \multirow{3}{*}{ Dukungan Sosial } & Rendah & 16 & 11,6 \\
& & Sedang & 27 & 19,6 \\
& & Tinggi & 95 & 68,8 \\
& & Total & 138 & 100 \\
\hline & & & & \\
\hline
\end{tabular}


Tabel 2. Gambaran pengalaman, dukungan sosial, pengetahuan, dan efikasi diri kader (Lanjutan)

\begin{tabular}{cclrc}
\hline No. & \multicolumn{2}{c}{ Karakteristik } & $\mathbf{n}$ & $\%$ \\
\hline 3 & \multirow{2}{*}{ Pengetahuan } & Rendah & 16 & 11,6 \\
& & Tinggi & 122 & 88,4 \\
& & Total & 138 & 100 \\
\multirow{2}{*}{4} & \multirow{2}{*}{ Efikasi Diri } & Rendah & 52 & 37,7 \\
& & Tinggi & 86 & 62,3 \\
& & Total & 138 & 100 \\
\hline
\end{tabular}

Uji multivariat regresi logistik menunjukkan bahwa faktor pengetahuan $(\mathrm{OR}=6,853, p=0,007)$, pengalaman $(O R=4,976, p=0,004)$, dan dukungan sosial $(O R=3,673$, $\mathrm{p}=0,033$ ) merupakan faktor dominan yang berhubungan dengan efikasi diri dalam melakukan deteksi dini gangguan jiwa. Pengetahuan merupakan faktor prediktor efikasi dengan odds rasio tertinggi. Model tersebut (Tabel 3) menunjukkan bahwa sumbangan pengaruh variabel independen (pengetahuan, pengalaman dan dukungan sosial) terhadap variasi efikasi diri sebesar $27,0 \%$, sedangkan sisanya sebesar $73 \%$ dipengaruhi oleh variabel lain yang tidak dimasukkan atau dibahas dalam penelitian ini.

Tabel 3. Hasil uji regresi logistik

\begin{tabular}{|c|c|c|c|c|c|}
\hline \multirow[t]{2}{*}{ Variabel } & \multirow{2}{*}{$\begin{array}{c}\text { Nilai } \\
\mathbf{p}\end{array}$} & \multirow[t]{2}{*}{ OR } & \multicolumn{2}{|c|}{$\begin{array}{c}\text { 95\% Confidence } \\
\text { Interval }\end{array}$} & \multirow{2}{*}{$\begin{array}{c}\mathbf{R} \\
\text { Square }\end{array}$} \\
\hline & & & $\begin{array}{l}\text { Lower } \\
\text { Bound }\end{array}$ & $\begin{array}{l}\text { Upper } \\
\text { Bound }\end{array}$ & \\
\hline Pengetahuan & 0,007 & 6,853 & 1,698 & 27,667 & 0,270 \\
\hline \multicolumn{6}{|l|}{ Pengalaman } \\
\hline Pengalaman (1) & 0,070 & 2,921 & 0,915 & 9,325 & \\
\hline Pengalaman (2) & 0,004 & 4,976 & 1,668 & 14,841 & \\
\hline \multicolumn{6}{|l|}{ Dukungan Sosial } \\
\hline Dukungan Sosial (1) & 0,608 & 1,439 & 0,359 & 5,768 & \\
\hline Dukungan Sosial (2) & 0,033 & 3,673 & 1,110 & 12,150 & \\
\hline Constant & 0,001 & 0,005 & & & \\
\hline
\end{tabular}

\section{DISKUSI}

Pengalaman, dukungan sosial, dan pengetahuan kader merupakan tiga faktor prediktor yang dapat menjelaskan sebagian dari efikasi diri kader dalam melakukan deteksi gangguan jiwa. Semakin baik pengalaman, dukungan sosial, dan pengetahuan kader akan semakin baik pula efikasi diri kader. Pengetahuan merupakan faktor prediktor yang paling dominan.

\section{DAFTAR PUSTAKA}

1. World Health Organization. The World Health Report. (O n I i n ) 2017 . http://www.who.int/csr/don/archive/year/2017/e n/ [diakses tanggal 22 Oktober 2017].

2. Badan Penelitian dan Pengembangan Kesehatan Kementerian Kesehatan RI. Riset Kesehatan Dasar (Riskesdas). (O n I i n e) 2013 . http://www.depkes.go.id/resources/download/ge neral/Hasil\%20Riskesdas\%202013.pdf [diakses tanggal 22 oktober 2017].
Penelitian ini sesuai dengan hasil penelitian yang dilakukan oleh Rias dan Pratama yang menyatakan terdapat hubungan yang signifikan antara pengetahuan dan efikasi diri pada caregiver $(6,12)$. Pengetahuan dapat menjadikan seseorang memiliki kesadaran sehingga berperilaku sesuai dengan pengetahuan yang dimilikinya (6). Perubahan perilaku yang dilandasi pengetahuan membuat kader yakin untuk melakukan deteksi dini gangguan jiwa tanpa paksaan tapi berdasarkan kesadaran kader sendiri. Semakin tinggi tingkat pendidikan seseorang akan meningkatkan kemampuannya dalam mendapatkan informasi sehingga meningkatkan pengetahuan (13). Peningkatan pengetahuan kader merupakan langkah yang sangat strategis untuk meningkatkan kemampuan pelayanan kader dalam melakukan deteksi dini gangguan jiwa (14).

Faktor prediktor efikasi yang lain adalah pengalaman. Cardone et al menyatakan bahwa pengalaman seseorang dapat meningkatkan efikasi dirinya dalam melakukan tugasnya (15). Unzuntiryaki juga mengidentifikasi bahwa diantara empat sumber informasi yang dapat mempengaruhi perkembangan efikasi diri, pengalaman keberhasilan merupakan yang paling berperan dalam meningkatkan efikasi diri (16). Pengalaman merupakan masa lalu atau kejadian yang akan menjadi penentu pada efikasi diri seseorang. Dalam kehidupan seseorang, keberhasilan menyelesaikan suatu masalah akan meningkatkan efikasi diri, sebaliknya kegagalan akan menurunkan efikasi diri (5). Kader yang memiliki pengalaman keberhasilan yang baik dalam melakukan deteksi dini dapat meningkatkan efikasi diri kader dalam melakukan deteksi dini gangguan jiwa dibandingkan dengan kader yang memiliki pengalaman keberhasilan yang rendah.

Sejalan dengan hasil penelitian ini, Sari dan Sumiati, juga Rizkia menemukan terdapat hubungan yang signifikan antara dukungan sosial dengan efikasi diri dalam menyelesaikan tugasnya $(17,18)$. Dukungan sosial yang diterima kader dapat berupa dukungan emosional, dukungan penghargaan, dukungan instrumental dan dukungan informasi (18). Dukungan sosial yang diterima oleh kader memiliki tingkatan yang berbeda beda. Dukungan sosial yang baik atau yang sesuai dengan apa yang dibutuhkan akan memberikan rasa nyaman dan dapat memunculkan keyakinan akan kemampuannya dalam melakukan tugasnya (7).

Penelitian ini mengidentifikasi tiga prediktor (pendidikan, pengalaman, dan dukungan sosial) efikasi diri kader dalam melakukan deteksi dini gangguan jiwa, dengan pengetahuan sebagai faktor dominan. Peningkatan pengetahuan melalui pelatihan serta pendampingan dalam praktik akan memperkuat efikasi diri kader.

3. Subu AM, Waluyo I, Edwin AN, Priscilla V, dan Aprina T. Stigma, Stigmatisasi, Perilaku Kekerasa dan Ketakutan Diantara Orang dengan Gangguan Jiwa (ODGJ) Di Indonesia: Penelitian Constructivist Grounded Theory. Jurnal Kedokteran Brawijaya. 2018; 30(1); 53-60.

4. Keliat BA, Helena N, dan Farida P. Manajemen Keperawatan Psikososial \& Kader Kesehatan Jiwa Comunity Mental Health Nursing. Jakarta: EGC; 2011; hal. 122.

5. Rustika IM. Efikasi Diri: Tinjauan Teori Albert 
Bandura. Buletin Psikologi. 2012; 20(1-2); 18-25.

6. Pratama DB dan Widodo A. Hubungan Pengetahuan dengan Efikasi Diri pada Caregiver Keluarga Pasien Gangguan Jiwa Di RSJD Dr. RM. Soedjarwadi. Jurnal Kesehatan. 2017; 10(1); 13-22.

7. Ni'mah A, Tadjri I, dan Kurniawan K. Hubungan Antara Dukungan Sosial dengan Self Eficacy dalam Menyelesaikan Skripsi. Indonesian Journal of Guidance and Counseling: Theory and Application. 2014; 3(1); 43-48.

8. Comton MT, Quintero L, and Esterberg ML. Assessing Knowlegde of Schizophrenia: Development and Psychometric Properties of a Brief, Multiple-Choice Knowledge Test for Use Across Various Samples. Psychiatary Research. 2007; 151(12); 87-95.

9. Al-Janabi H, Coast J, and Flynn TN. What Do People Value When They Provide Unpaid Care for an Older Person? A Meta-Ethnography with Interview FollowUp. Social Science \& Medicine. 2008; 67(1); 111-121.

10. Schulz U and Schwarzer R. Soziale Unterstutzung Bei Der Krankheitsbewaltigung Die Berliner Social Support Skalen (BSSS) [Social Support In Coping With IIIness: The Berlin Social Support Scales (BSSS). Diagnostica. 2003; 49(2); 73-82.

11. Scholz U, Dona GB, Sud S, and Schwarzer R. Is General Self-Efficacy A Universal Construct?Psychometric Findings from 25 Contries. European Journal of Psychological Assesment. 2002; 18(3); 242-251.

12. Rias YA. Hubungan Pengetahuan dan Keyakinan dengan Efikasi Diri Penyandang Diabetic Foot Ulcer. Jurnal Keperawatan Muhammadiyah. 2016; 1(1); 1317.

13. Sulaiman ES, Murti B, dan Waryana W. Aplikasi Model Precede-Proceed pada Perencanaan Program Pemberdayaan Masyarakat Bidang Kesehatan Berbasis Penilaian Kebutuhan Kesehatan Mayarakat. Yarsi Medical Journal. 2015; 23(3); 149164.

14. Khoddam H, Mehrdad N, Peyrovi H, Kitson AL, Schultz TJ, and Athlin AM. Knowledge Translation In Health Care: A Concept Analysis. Medical Journal of the Islamic Republic of Iran. 2014; 28(98): 1-15.

15. Candona IS, Rodriguez-Montalban R, Acevedo-Soto E, Lugo KN, Torres-Oquendo F, and Torro-Alfonso J. Self Efficacy and Opennes to Experience as Antecedent of Study Engagement: An Exploratory Analysis. Procedia-Social and Behavioral Sciences. 2012; 46; 2163-2167.

16. Uzuntiryaki E. Expoloring The Sources of Turkish PreSrive Che-Mistry Teachers Chemistry Self Efficacy Beliefs. Australia Journal of Teacher Educatioan. 2008; 33(6); 12-28.

17. Sari A dan Sumiati A. Hubungan antara Dukungan Sosial dengan Efikasi Diri pada Siswa Kelas X Akutansi di SMK Bina Pangudi Luhur Jakarta. Jurnal Ilmiah Econosains. 2016; 14(2); 126-138.

18. Rizkia F dan Dewi KD. Hubungan antara Dukungan Sosial Dengan Self Efficacy Pada Mahasiswa Fakultas IImu Pendidikan Universitas Negeri Surabaya Angkatan Tahun 2015. Jurnal Penelitian Psikologi. 2017; 4(1); 1-7. 